\title{
DETERIORAÇÃO CONTROLADA EM SEMENTES DE BETERRABA ${ }^{1}$
}

\author{
JOSUÉ BISPO DA SILVA²; ROBERVAL DAITON VIEIRA ${ }^{3}$
}

\begin{abstract}
RESUMO - O uso de testes de vigor é fundamental na avaliação do potencial fisiológico de sementes produzidas e comercializadas. O trabalho foi realizado com o objetivo de estudar o uso do teste de deterioração controlada na avaliação do potencial fisiológico de sementes de beterraba. Após lavagem dos frutos contendo as sementes em água corrente, oito lotes da cultivar Top Tall Early Wonder foram previamente avaliados pelos testes de germinação e de emergência de plântulas (EP). Para o ajuste do teor de água (TA) foram estudados os métodos de atmosfera úmida (AU) e substrato úmido (SU). O teste de deterioração controlada (DC) foi conduzido com 22 e $24 \%$ de água e exposição durante 12 , 24 e 36 horas à temperatura de $45^{\circ} \mathrm{C}$. Usou-se o delineamento experimental inteiramente casualizado, com oito repetições de 25 sementes, exceto o de EP, conduzido com quatro repetições de 50 sementes. Os dados foram analisados separadamente para cada combinação TA x períodos de deterioração e as médias comparadas usando-se o teste de Tukey $(\mathrm{P} \leq 0,05)$. Análises de correlação simples foram estabelecidas entre os resultados dos testes de laboratório e a EP. O ajuste do TA de semente deve ser feito pelo método do SU. O teste de DC pode ser utilizado para avaliar o potencial fisiológico de sementes de beterraba, sendo indicada a combinação TA de $22 \%$, a $45^{\circ} \mathrm{C}$, durante 24 horas.
\end{abstract}

Termos para indexação: Beta vulgaris, germinação, vigor, emergência de plântulas.

\section{CONTROLLED DETERIORATION OF BEETROOT SEEDS}

\begin{abstract}
The vigor test is a fundamental test used to evaluate the physiological potential of produced and commercialized seeds. Controlled deterioration was studied as a method to evaluate the physiological potential of beetroot seeds (Beta vulgaris). After immersing the fruits in running water, eight seed lots of cultivar Top Tall Early Wonder were evaluated as to germination and seedling emergence. The seed water content (SWC) was adjusted using the wet atmosphere and moist substrate methods. The controlled deterioration test was a completely randomized design with eight replicates of 25 seeds and was conducted at $45^{\circ} \mathrm{C}$ using a SWC of $22 \%$ or $24 \%$ and deterioration times of 12,24 and 36 hours. The experimental design for seedling emergence tests was also completely randomized but used four replicates of 50 seeds. The data were statistically analyzed for each combination of SWC and deterioration period separately and the means compared by the Tukey test $(\mathrm{p} \leq 0.05)$. Simple correlation analysis was run using the data from seed laboratory tests and seedling emergence. The results indicate that SWC adjustment should be carried out only using the moist substrate method. Physiological potential of beetroot seeds can be evaluated using the controlled deterioration test with parameters of $45^{\circ} \mathrm{C}, 24$ hours and $22 \%$ SWC.
\end{abstract}

Index terms: Beta vulgaris, germination, seedling emergence, vigor.

${ }^{1}$ Submetido em 19/03/2009. Aceito para publicação em 26/06/2009.Parte da Tese do primeiro autor apresentada à UNESP/FCAV.

${ }^{2}$ Professor Adjunto, Centro de Ciências Biológicas e da Natureza, UFAC, BR 364, km 4, 69915-900, Rio Branco, AC, Brasil. <josuebispo@bol.com.br>
${ }^{3}$ Professor Titular, Depto. Produção Vegetal, UNESP, Via de Acesso Prof. Paulo Donato Castellane, s/n, 14884-900, Jaboticabal, SP, Brasil. <rdvieira@fcav.unesp.br> 


\section{INTRODUÇÃO}

A germinação de sementes de Beta vulgaris é freqüentemente baixa ou irregular, razão pela qual o período compreendido entre a semeadura e a emergência de plântulas representa uma das fases críticas do ciclo da cultura (Durrant et al., 1985). Assim, a uniformidade e a porcentagem de emergência assumem grande importância no rendimento e na qualidade final do produto (Durrant et al., 1983). Isso reforça a necessidade de se desenvolver procedimentos mais adequados para avaliação do potencial fisiológico de sementes dessa espécie.

O teste de deterioração controlada tem sido usado na avaliação do potencial fisiológico de sementes, particularmente de espécies olerícolas como colza, nabo, alho, alface, couve (Powell e Matthews, 1981; Powell et al., 1984; Larsen et al., 1998), couve-flor (Matthews, 1998), ervilha (Powell et al., 1997), cebola (Powell e Matthews, 1984), cenoura (Powell, 1995; Rodo et al., 2000), brócolis (Mendonça et al., 2000, 2003) e beterraba (Silva et al., 2006), utilizando combinações de teor de água/temperatura/período de exposição que variaram de 15 a $24 \%, 40$ a $45^{\circ} \mathrm{C}$ e 12 a 72 horas, respectivamente. Em alguns trabalhos, os resultados desse teste têm também se correlacionado com a emergência de plântulas (Powell e Matthews, 1981; Matthews, 1998).

Para sementes de Beta vulgaris, embora a combinação $24 \% / 45^{\circ} \mathrm{C} / 24 \mathrm{~h}$ tenha proporcionado resultados promissores (Powell, 1995), as pesquisas ainda devem continuar, uma vez que novos cultivares podem apresentar comportamento diferenciado frente às condições impostas pelo teste. Além da temperatura, os fatores teor de água de semente e o período de exposição também merecem estudos, para que se possa caminhar no sentido da padronização do teste de deterioração controlada.

A presente pesquisa teve como objetivo desenvolver protocolos para a condução do teste de deterioração controlada para semente de Beta vulgaris e verificar a relação entre os resultados desse teste e a emergência de plântulas.

\section{MATERIAL E MÉTODOS}

O trabalho foi realizado no Laboratório de Análise de Sementes e no Setor de Olericultura e Plantas AromáticoMedicinais do Departamento de Produção Vegetal, Universidade Estadual Paulista - UNESP, Câmpus de Jaboticabal, SP.

Foram utilizados pixídios (frutos), popularmente denominados sementes, da cultivar Top Tall Early Wonder, de oito lotes, adquiridos de empresas produtoras e mantidos embalados hermeticamente, dentro de câmara regulada a $10{ }^{\circ} \mathrm{C}$, até o início dos testes.

Antes dos testes de laboratório e emergência de plântulas, as sementes foram lavadas em água corrente durante duas horas, tratadas quimicamente com fungicida após a lavagem (Thiram 0,2\%) e secadas em temperatura ambiente de aproximadamente $25^{\circ} \mathrm{C}$, com auxílio de ventiladores (Silva et al., 2005).

O teor de água de semente (TA) foi determinado com amostras de aproximadamente $2 \mathrm{~g}$ de cada lote, em duas repetições colocadas em estufa a $130 \pm 3{ }^{\circ} \mathrm{C}$ por uma hora (ISTA, 1999), antes da lavagem das sementes em água corrente e após o ajuste do TA para o teste de deterioração controlada.

Foram estudados dois procedimentos para o ajuste do TA das sementes: a metodologia da atmosfera úmida (AU) e a do substrato úmido (SU), propostas por Rosseto et al. (1995). Na primeira, uma amostra contendo 13,2 g de sementes de cada lote foi acondicionada sobre tela, em caixa plástica de germinação $(11 \times 11 \times 3 \mathrm{~cm})$, contendo $40 \mathrm{~mL}$ de água desionizada e mantida em câmara a $20^{\circ} \mathrm{C}$. Na segunda, a mesma massa de sementes de cada lote foi colocada entre duas camadas de três folhas de papel, tipo Germitest, umedecidas com água desionizada na proporção de três vezes a massa do papel não hidratado e igualmente mantida a $20{ }^{\circ} \mathrm{C}$. Em ambos os métodos, a massa das sementes de cada amostra foi monitorada, em intervalos de 15 minutos e, em seguida, o TA ajustado usando-se a equação $\mathrm{M}_{\mathrm{f}}=[(100$ - A) x $\left.(100 \text { - B })^{-1}\right] \times M_{i}$, onde: $M_{f}=$ massa final, $M_{i}=$ massa inicial e A e B correspondem aos TA inicial e desejado, respectivamente.

Para a realização do teste de germinação (TG), oito repetições de 25 sementes de cada lote foram colocadas em caixas plásticas de germinação, sobre duas folhas de papel de filtro umedecidas com água desionizada, na proporção de três vezes a massa do papel não hidratado. As caixas com as sementes foram colocadas em câmara de germinação a $20{ }^{\circ} \mathrm{C}$. A avaliação do teste foi diária, do quarto ao $14^{\circ}$ dia; foi considerada apenas a primeira plântula de cada sementepixídio (ISTA, 1999).

A emergência de plântulas (EP) foi conduzida em casa de vegetação tipo arco, com comprimento, largura e altura do pé-direito de $15 \times 7 \times 4,5 \mathrm{~m}$, respectivamente, fechada lateralmente com tela anti-afídeos e coberta com polietileno transparente, aditivado contra radiação ultravioleta, com espessura de $100 \mu \mathrm{e}$ transmissividade à radiação solar global de 70 a $80 \%$. Quatro repetições de 50 sementes por lote foram 
distribuídas a $3 \mathrm{~cm}$ de profundidade, em substrato comercial Plantmax $^{\circledR}$, constituído pela mistura de casca de pinus, vermiculita e fertilizante, em bandejas de polipropileno, com 72 células de $8 \mathrm{~cm}$ de profundidade, mantidas sobre bancada, a um metro da superfície do solo. O substrato foi umedecido duas vezes ao dia (manhã e tarde). A contagem das plântulas emergidas ocorreu diariamente, até o 14ํ dia. A temperatura e a umidade relativa do ar foram avaliadas por meio de termohigrógrafo instalado ao lado das bandejas de semeadura. A temperatura do substrato foi monitorada às profundidades de 2 e $6 \mathrm{~cm}$, em células aleatórias, por meio de termopares de cobre-constantan e os dados registrados em Data-Logger 21x.

A metodologia para o teste de deterioração controlada teve por base o trabalho de Powell (1995), ou seja, após a determinação do procedimento que permitiu o ajuste do TA para os valores pré-determinados, amostras de sementes de cada lote foram colocadas para embeber a $20{ }^{\circ} \mathrm{C}$, até que atingiram os TA de 22 e $24 \%$. Obtidos os valores desejados, cada amostra foi acondicionada hermeticamente em embalagens de plástico aluminizado e mantidas em câmara a $10{ }^{\circ} \mathrm{C}$ por 72 horas, para atingir o equilíbrio higroscópico. Em seguida, foram colocadas e mantidas em banho-maria, a $45{ }^{\circ} \mathrm{C}$, durante 12,24 e 36 horas. Na seqüência, foram retiradas do banho-maria e mergulhadas em água fria por, aproximadamente, 30 minutos, para redução da temperatura. Instalou-se o teste de germinação (ISTA, 1999) conforme descrito. A avaliação foi realizada aos sete dias após a semeadura e os resultados expressos em porcentagem de plântulas normais.

O delineamento experimental utilizado foi o inteiramente ao acaso, com oito repetições de 25 sementes, exceto no EP, conduzido com quatro repetições de 50 sementes. No teste de DC, foram avaliados oito tratamentos (lotes), analisados separadamente para cada combinação TA x período de exposição. As médias foram comparadas usando-se o teste de Tukey $(\mathrm{P} \leq 0,05)$ (Banzatto e Kronka, 1995). Análises de correlação simples foram estabelecidas entre os resultados dos testes de laboratório e a EP. Os dados de TA das sementes não foram analisados estatisticamente.

\section{RESULTADOS E DISCUSSÃO}

Os resultados referentes ao teor de água das sementes (TA) antes e após a deterioração controlada são apresentados na Tabela 1. O TA médio entre os lotes foi de $8,5 \%$ após a lavagem e respectiva secagem, com variação de 1,7 ponto percentual entre os extremos e correspondeu aos valores encontrados antes da lavagem. $\mathrm{O}$ uso de sementes com TA inicial semelhante é importante no procedimento de embebição que deve ser realizado antes do teste de deterioração controlada (DC), pois possibilita que todos os lotes atinjam os valores pré-estabelecidos em período próximo, agilizando assim o início da fase de banho-maria.

$\mathrm{O}$ ajuste preciso do TA é pré-requisito fundamental para a obtenção de resultados confiáveis no teste de DC, pois diferenças quanto ao TA entre sementes de diferentes lotes ou de um único lote podem levá-las a taxas de deterioração desiguais. A diferença máxima entre os extremos foi de 0,6 ponto percentual (Tabela 1) para os dois valores préestabelecidos. Dessa forma, trabalhando com teor de água constante e pré-determinado, tornou-se possível a comparação do nível de deterioração dos lotes, bem como classificá-los quanto ao vigor (Roberts, 1973).

TABELA 1. Teor de água inicial (TAi) e após o ajuste para os valores estabelecidos de $22 \%$ (TA22) e 24\% (TA24) para o teste de deterioração controlada em oito lotes de sementes de beterraba.

\begin{tabular}{|c|c|c|c|c|c|c|c|c|}
\hline \multirow{3}{*}{ TA } & \multicolumn{8}{|c|}{ Lotes } \\
\hline & 1 & 2 & 3 & 4 & 5 & 6 & 7 & 8 \\
\hline & \multicolumn{8}{|c|}{ - - - - - - - - - - - - - - - \% - - - - - - - - - - - - - } \\
\hline TAi & 8,6 & 8,4 & 7,9 & 7,6 & 8,4 & 9,3 & 9,2 & 8,2 \\
\hline TA22 & 22,1 & 22,3 & 21,7 & 21,9 & 22,2 & 21,8 & 21,8 & 22,0 \\
\hline TA24 & 23,9 & 24,0 & 23,9 & 23,9 & 23,7 & 23,8 & 23,5 & 24,1 \\
\hline
\end{tabular}

No ajuste do teor de água das sementes (TA) a metodologia da atmosfera úmida (AU), embora seja considerada mais segura por reduzir ao mínimo o risco de danos fisiológicos às sementes (Marcos Filho e Novembre, 2009), não se mostrou adequada, uma vez que o valor máximo alcançado foi de $22 \%$ para a maioria dos lotes, ficando praticamente inalterado a partir de 135 horas de condicionamento, ao passo que os valores pré-estabelecidos para esse parâmetro foram não somente de $22 \%$, mas também de 24\% (Figura 1). 


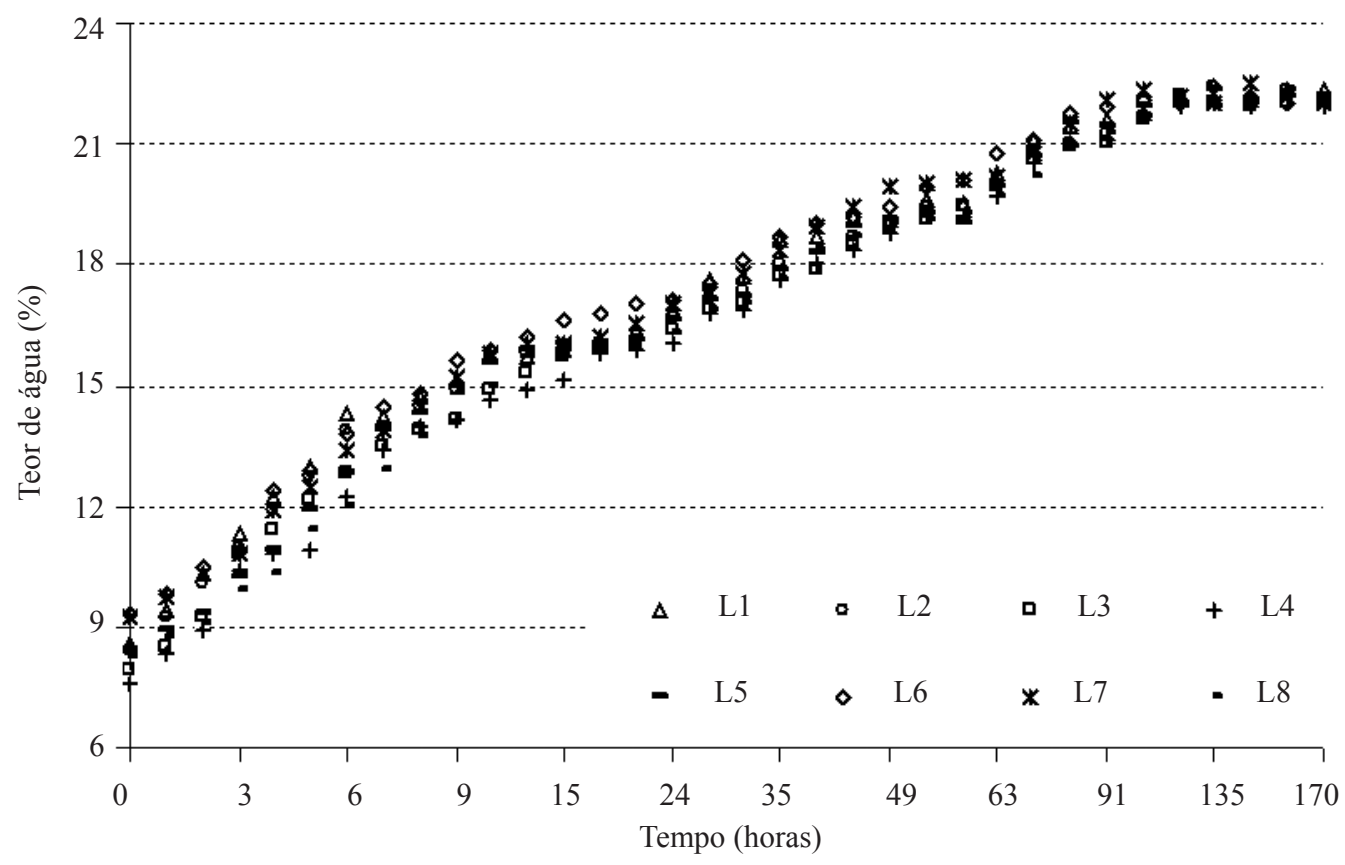

FIGURA 1. Variação no teor de água de sementes de beterraba provenientes de oito lotes, em função do período de condicionamento pelo método da atmosfera úmida.

Uma possível explicação para a dificuldade em elevar o TA para valores superiores a $22 \%$ pelo método da AU é que os frutos de beterraba (pixídios) são formados por um espesso pericarpo corticoso (Filgueira, 2000) que envolve a semente verdadeira, material que pode restringir a absorção de água (Carvalho e Nakagawa, 2000), principalmente em ambientes onde a disponibilidade hídrica é limitada.

Já o método do substrato úmido (SU) possibilitou a elevação do TA das sementes até os níveis desejados (22 e $24 \%$ ), em aproximadamente 1 hora e 40 minutos (Figura 2). Considerando a baixa umidade inicial das sementes $(8,5 \%)$, um rápido aumento no teor de água poderia causar desintegração em nível celular, com conseqüências negativas sobre o potencial fisiológico. No entanto, a embebição nesse período pode ser considerada lenta e incapaz de causar injúrias às membranas celulares das sementes, que apresentaram níveis de germinação aceitáveis (Tabela 3 ).

$\mathrm{O}$ ajuste do TA no SU em tempo menor que na $\mathrm{AU}$ foi devido, provavelmente, à maior disponibilidade hídrica e maior área de contato entre as sementes e o substrato umedecido, fatores que, segundo Carvalho e Nakagawa (2000), interferem na velocidade de absorção de água, além da espécie e da temperatura.
Os resultados referentes à germinação (TG) e à emergência de plântulas (EP) são apresentados na Tabela 2. No TG, os lotes apresentaram desempenho satisfatório, exceto o lote 8 . Devido ao desempenho acentuadamente inferior desse lote em relação aos outros, ele poderia ter sido eliminado da pesquisa, pois segundo Marcos Filho (1999), é coerente a comparação de lotes considerados estatisticamente semelhantes no teste de germinação e cujos valores sejam iguais ou superiores ao considerado como comercialmente aceitável, que, para sementes dessa espécie, é de $80 \%$ (Filgueira, 2000). Entretanto, mesmo não tendo apresentado desempenho suficiente para atender a essa recomendação, optou-se pela continuidade da utilização desse lote, para que fosse possível determinar se essa aparente inferioridade foi devida ao baixo potencial fisiológico de suas sementes ou se outros fatores poderiam ter influenciado esse resultado.

$\mathrm{Na} \mathrm{EP}$, a temperatura média do ar, que durante o período de condução do experimento foi de $23{ }^{\circ} \mathrm{C}$, é um fator que exerce grande influência sobre o processo germinativo (Carvalho e Nakagawa, 2000), mas nesse ambiente não se constituiu em obstáculo, uma vez que sementes de beterraba germinam sob temperaturas que variam de 4 a 30 ${ }^{\circ} \mathrm{C}$, com melhor desempenho entre 18 e $24{ }^{\circ} \mathrm{C}$ (Swiader et al., 1992). 


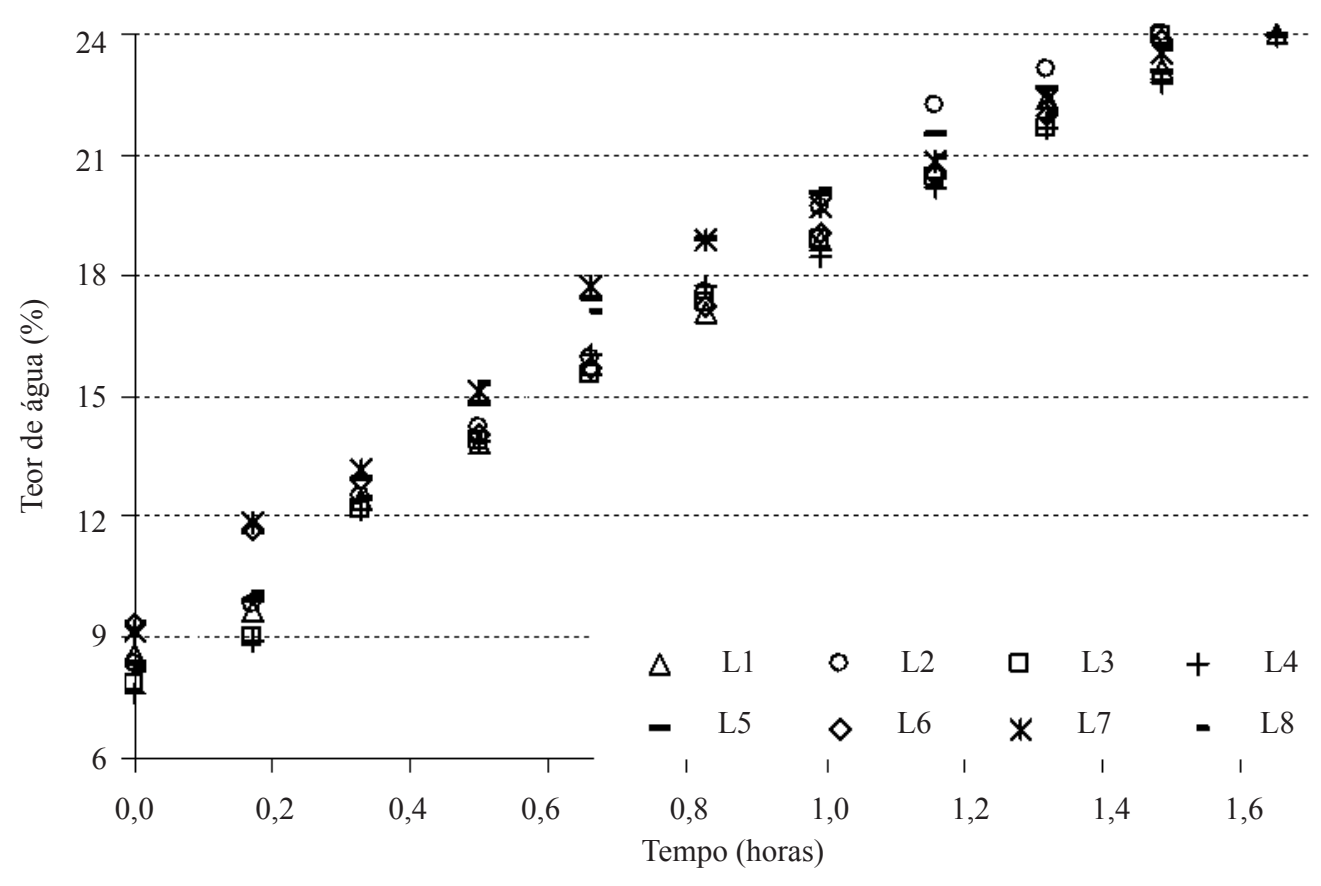

FIGURA 2. Variação no teor de água de sementes de beterraba provenientes de oito lotes, em função do período de condicionamento pelo método do substrato úmido.

TABELA 2. Avaliação da germinação (G) e emergência de plântulas (EP) de oito lotes de sementes de beterraba.

\begin{tabular}{|c|c|c|c|c|c|c|c|c|c|c|}
\hline \multirow{3}{*}{ Testes } & \multicolumn{8}{|c|}{ Lotes } & \multirow[t]{2}{*}{ Média } & \multirow[t]{2}{*}{ C.V. } \\
\hline & 1 & 2 & 3 & 4 & 5 & 6 & 7 & 8 & & \\
\hline & \multicolumn{10}{|c|}{ - - - - - - - - - - - - - - } \\
\hline G & $94 \mathrm{a}$ & $90 \mathrm{a}$ & $93 \mathrm{a}$ & $89 \mathrm{a}$ & $89 \mathrm{a}$ & $92 \mathrm{a}$ & $90 \mathrm{a}$ & $74 \mathrm{~b}$ & 89 & 6,14 \\
\hline EP & $97 \mathrm{a}$ & $87 b c$ & $97 \mathrm{a}$ & $86 b c$ & $86 b c$ & $94 a b c$ & $86 b c$ & $85 c$ & 90 & 5,22 \\
\hline
\end{tabular}

Médias seguidas por letras distintas diferem entre si ao nível de $5 \%$ de probabilidade no Teste de Tukey.

As temperaturas máxima e mínima do substrato variaram de 18 a $29^{\circ} \mathrm{C}$ a $2 \mathrm{~cm}$ de profundidade e de 19 a 27 ${ }^{\circ} \mathrm{C}$ a $6 \mathrm{~cm}$, no dia nublado, e de 10 a $32{ }^{\circ} \mathrm{C}$ a $2 \mathrm{~cm}$ e de 11 a $30{ }^{\circ} \mathrm{C}$ a $6 \mathrm{~cm}$, no dia claro, respectivamente. Esse parâmetro também não se constituiu obstáculo à germinação.

A germinação média verificada na EP ficou muito próxima à do TG. Por ser conduzido sob condições ideais para o processo germinativo, é de se esperar que o TG superestime o potencial de germinação dos lotes de sementes, em relação à $\mathrm{EP}$, o que não ocorreu neste trabalho. $\mathrm{O}$ baixo valor do lote 8 no TG pode ser a causa desse resultado discrepante e, embora tenha sido considerado inicialmente inferior aos demais, seu desempenho na EP foi de 11 pontos percentuais acima do obtido naquele teste. Deve- se ressaltar, também, que as sementes ficaram armazenadas por aproximadamente seis meses até o início da EP, o que pode ter eliminado possíveis resquícios de dormência que ainda restavam, favorecendo o processo germinativo.

No teste de DC, o percentual médio de germinação ficou próximo nos dois TA e seus respectivos períodos (Tabela 3). Em sementes com TA de $22 \%$, o período de 24 horas indicou a superioridade dos lotes 1 e 3 , resultado também verificado na EP (Tabela 2). Nas sementes com TA de $24 \%$, os períodos cujos resultados mais se assemelharam ao da EP foram os de 12 e 36 horas, que evidenciaram a superioridade dos lotes 1 e 3 . Esse último período, no entanto, foi muito drástico às sementes, reduzindo sensivelmente a germinação. 
TABELA 3. Germinação de sementes de beterraba de oito lotes, avaliada pelo teste de deterioração controlada, a $45^{\circ} \mathrm{C}$, em função do teor de água e do período de exposição.

\begin{tabular}{|c|c|c|c|c|c|c|}
\hline \multirow{3}{*}{ Lotes } & \multicolumn{3}{|c|}{$22 \%$} & \multicolumn{3}{|c|}{$24 \%$} \\
\hline & $12 \mathrm{~h}$ & $24 \mathrm{~h}$ & $36 \mathrm{~h}$ & $12 \mathrm{~h}$ & $24 \mathrm{~h}$ & $36 \mathrm{~h}$ \\
\hline & \multicolumn{6}{|c|}{ 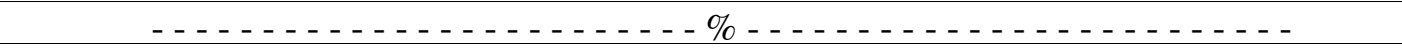 } \\
\hline 1 & $91 \mathrm{ab}$ & $94 a$ & $82 \mathrm{ab}$ & $94 \mathrm{a}$ & $83 a b$ & $74 \mathrm{a}$ \\
\hline 2 & $75 \mathrm{~cd}$ & $71 \mathrm{bc}$ & $52 d$ & $77 \mathrm{bc}$ & $68 \mathrm{c}$ & $62 \mathrm{abc}$ \\
\hline 3 & $95 \mathrm{a}$ & $94 \mathrm{a}$ & $83 \mathrm{a}$ & $95 a$ & $89 a$ & $74 a$ \\
\hline 4 & $78 \mathrm{bcd}$ & $71 b c$ & 69abc & $80 \mathrm{bc}$ & $65 c$ & $52 \mathrm{~cd}$ \\
\hline 5 & $66 \mathrm{~d}$ & $64 c$ & $68 b c$ & $68 c$ & $72 b c$ & $58 \mathrm{bc}$ \\
\hline 6 & $78 \mathrm{bcd}$ & $79 b c$ & $72 \mathrm{abc}$ & $83 a b$ & $70 \mathrm{bc}$ & $57 \mathrm{bc}$ \\
\hline 7 & $74 \mathrm{~cd}$ & $63 c$ & $58 \mathrm{~cd}$ & $81 \mathrm{abc}$ & $61 \mathrm{c}$ & $42 d$ \\
\hline 8 & $76 \mathrm{~cd}$ & $68 \mathrm{bc}$ & $69 \mathrm{abc}$ & $75 \mathrm{bc}$ & $80 \mathrm{ab}$ & $70 b c$ \\
\hline Média & 79 & 76 & 69 & 82 & 74 & 61 \\
\hline C.V. & 10,50 & 11,13 & 16,48 & 8,20 & 12,19 & 18,18 \\
\hline
\end{tabular}

Médias seguidas por letras distintas, na coluna, diferem entre si ao nível de 5\% de probabilidade no Teste de Tukey.

De um modo geral, as combinações $22 \% / 24$ h e $24 \% / 12$ h mostraram-se promissoras para o escalonamento dos lotes no teste de DC. Entretanto, Silva et al. (2006), estudando o teste de DC em sementes de cinco lotes da mesma espécie e cultivar utilizadas no presente trabalho, submetidas a 41 e $45^{\circ} \mathrm{C}$, com teores de água de 22,24 e $26 \%$, durante 12 , 24 e 36 horas, verificaram que a melhor combinação para classificação dos lotes em níveis de vigor foi a de

$45^{\circ} \mathrm{C} / 24 \% / 24 \mathrm{~h}$.

Os resultados evidenciaram que os diferentes procedimentos para a condução do teste de DC foram suficientes para deteriorar as sementes. A queda no desempenho germinativo ocorre porque a exposição de sementes a altas temperatura e umidade relativa do ar provoca alterações que influenciam a síntese de proteínas, de ácidos nucléicos e o metabolismo do DNA (Vásquez et al., 1991). Ocorrem, também, alterações no processo respiratório e na funcionalidade das membranas (Basajavarajappa et al., 1991), cuja causa principal é a peroxidação de lipídios (McDonald, 1999), com interferência relevante sobre a germinação.

Entre as características desejáveis em um teste de vigor está a relação com a emergência de plântulas (Marcos Filho, 1999). Essa relação foi verificada por meio da determinação dos valores de correlação simples entre os resultados dos testes de laboratório e a emergência de plântulas. O baixo valor do coeficiente de correlação $(r=0,614 \mathrm{~ns})$ indica que as condições encontradas no teste de germinação (TG) em laboratório não foram as mesmas do teste de emergência de plântulas (EP), não obstante a temperatura verificada na casa de vegetação ter permanecido dentro da faixa considerada ótima para a germinação de sementes de beterraba (Swiader et al., 1992) e essas terem recebido suplementação hídrica. Nesse caso, o baixo desempenho do lote 8 no TG pode ter sido a causa da não significância observada. Se esse lote tivesse apresentado valores de germinação próximos aos dos outros lotes no TG, possivelmente a correlação seria significativa, pois as condições ocorridas na casa de vegetação foram, aparentemente, favoráveis ao desenvolvimento do processo germinativo.

Durrant et al. (1985) verificaram que o TG é um procedimento confiável para estimar o desempenho de sementes dessa espécie em condições de campo, resultado que, sem o lote 8 , possivelmente também teria sido possível obter.

$\mathrm{Na}$ análise de correlação entre a EP e o teste de DC, as combinações que apresentaram correlação significativa foram $22 \% / 24 \mathrm{~h}(\mathrm{r}=0,727 ; \mathrm{P} \leq 0,05)$ e $24 \% / 24 \mathrm{~h}(\mathrm{r}=0,872$; $\mathrm{P} \leq 0,01)$. Embora seja recomendado comparar os resultados dos testes de laboratório com os de emergência de plântulas em campo (Egli e TeKrony, 1995), o uso exclusivo de correlações para a avaliação da eficiência dos testes de vigor pode levar à obtenção de informações imprecisas (Marcos Filho et al., 1984), como ocorreu na combinação 24\%/24 h que, embora mostrou correlação superior à de $22 \% / 24 \mathrm{~h}$, não teve a mesma precisão na classificação dos lotes, que é um dos principais objetivos dos testes de vigor. 
Estudando a possibilidade de se estabelecer relação entre os resultados dos testes para avaliar o potencial fisiológico de sementes em laboratório e o seu desempenho em campo, diversos pesquisadores observaram que esta relação pode, muitas vezes, ser incompatível (Vieira et al., 1994), em virtude, provavelmente, de os testes de emergência de plântulas nem sempre serem adequados para detectar diferenças entre o potencial fisiológico dos lotes de sementes (Marcos Filho, 1999) e, também, porque, em função das condições ambientais na semeadura, um determinado teste pode estimar melhor a emergência de plântulas do que outro (Albuquerque, 2000).

Os resultados desse trabalho, no entanto, mostram que o procedimento destacado para avaliação do potencial fisiológico $(22 \% / 24 \mathrm{~h})$, além de separar os lotes em níveis distintos de vigor, apresentou correlação significativa $(\mathrm{P} \leq$ $0,05)$ com a emergência de plântulas. Porém, uma correlação significativa indica haver uma tendência de variação semelhante entre duas características, mas não significa que existe a correspondente precisão de estimativa de qualidade do lote (Tekrony e Egli, 1977; Marcos Filho et al., 1984).

Desse modo, o teste de DC, associado ao de emergência de plântulas e a outros testes de vigor, pode ser utilizado com relativa segurança na avaliação do vigor de sementes de beterraba, ainda que com sensibilidade diferente. No entanto, o potencial dos diferentes procedimentos para estimar o desempenho dos lotes em campo pode diminuir caso as condições ambientais sejam diferentes das verificadas nessa pesquisa.

\section{CONCLUSÕES}

A hidratação das sementes de beterraba para o teste de deterioração controlada deve ser feita entre papel; a combinação $22 \% / 24 \mathrm{~h} / 45{ }^{\circ} \mathrm{C}$ é a mais indicada para a avaliação do potencial fisiológico de sementes neste teste.

\section{REFERÊNCIAS}

ALBUQUERQUE, M.C.F. Desempenho germinativo e testes de vigor para sementes de girassol, milho e soja, semeadas sob condições de estresse ambiental. 2000. 180f. Tese (Doutorado em Produção e Tecnologia de Sementes) - Universidade Estadual Paulista, Jaboticabal, 2000 .

BANZATTO, D.A.; KRONKA, S.N. Experimentação agrícola. 3.ed. Jaboticabal: FUNEP, 1995. 247p.
BASAJAVARAJAPPA, B.S.; SHETY, H.S.; PRAKASH, H.S. Membrane deterioration and other biochemical changes, associated with accelerated aging of maize seeds. Seed Science and Technology, v.2, n.2, p.279-286, 1991.

CARVALHO, N.M.; NAKAGAWA, J. (Ed.). Sementes: ciência, tecnologia e produção. 4.ed. Jaboticabal: FUNEP, 2000. 588p.

DURRANT, M.J.; BROWN, S.; BOULD, A. The assessment of the quality of sugar-beet seed. Journal of Agricultural Science, v.104, p.71-84, 1985.

DURRANT, M.J.; PAYNE, P.A.; McLAREN, J.S. The use of water and some inorganic salt solutions to advance sugar beet seed. I. Laboratory studies. Annals of Applied Biology, v.103, n.3, p.507-515, 1983.

EGLI, D.B.; TEKRONY, D.M. Soybean seed germination, vigor and field emergence. Seed Science and Technology, v.23, n.3, p.595-607, 1995.

FILGUEIRA, F.A.R. Novo manual de olericultura: agrotecnologia moderna na produção e comercialização de hortaliças. Viçosa: UFV, 2000. 402p.

INTERNATIONAL SEED TESTING ASSOCIATION. International rules for seed testing. Seed Science and Technology, v.27, p.1-333, 1999. (Supplement)

LARSEN, S.U., POVLSEN, F.V., ERIKSEN, E.N., PEDERSEN, H.C. The influence of seed vigour on field performance and the evaluation of the applicability of the controlled deterioration vigour test in oil seed rape (Brassica napus) and pea (Pisum sativum). Seed Science and Technology, v.26, n.3, p.627-41, 1998.

MARCOS FILHO, J. Testes de vigor: importância e utilização. In: KRZYZANOWSKI, F.C.; VIEIRA, R.D.; FRANÇA NETO, J.B. (Ed.). Vigor de sementes: conceitos e testes. Associação brasileira de tecnologia de sementes, Comitê de vigor de sementes. Londrina: ABRATES, 1999. cap.1, p.1-21.

MARCOS FILHO, J.; NOVEMBRE, A.D.L.C. Avaliação do potencial fisiológico de sementes de hortaliças. In: NASCIMENTO, W.M. (Ed.). Tecnologia de sementes de hortaliças. Brasília: Embrapa Hortaliças, 2009. p.185243.

MARCOS FILHO, J.; PESCARIN, H.M.C.; KOMATSU, Y.H.; DEMÉTRIO, C.G.B.; FANCELLI, A.L. Testes para avaliação do vigor de sementes de soja e suas relações com emergência de plântulas no campo. Pesquisa Agropecuária Brasileira, v.19, n.5, p.605-613, 1984. 
MATTHEWS, S. Approaches to the indirect evaluation of germination and vigour. Scientia Agrícola, v.55, n.esp., p.62-66, 1998.

McDONALD, M.B. Seed deterioration: physiology, repair and assessment. Seed Science and Technology, v.27, n.1, p.177-237, 1999.

MENDONÇA, E.A.F.; RAMOS, N.P.; FESSEL, S.A. Adequação da metodologia do teste de deterioração controlada para sementes de brócolis. Revista Brasileira de Sementes, v.25, n.1, p.18-24, 2003.

MENDONÇA, E.A.F.; RAMOS, N.P.; FESSEL, S.A.; SADER, R. Teste de deterioração controlada em sementes de brócolis. Revista Brasileira de Sementes, v.22, n.2, p.280-287, 2000.

POWELL, A.A. The controlled deterioration test. In: VERTER, H.A. van de. Seed vigour testing seminar. Zürich: ISTA, 1995. p.73-87.

POWELL, A.A.; MATTHEWS, S. Evaluation of controlled deterioration, a new vigour test for small seed vegetables. Seed Science and Technology, v.9, n.2, p.633-640, 1981.

POWELL, A.A.; MATTHEWS, S. Prediction of the storage potential of onion seed under commercial storage conditions. Seed Science and Technology, v.12, n.2, p.641-647, 1984.

POWELL, A.A.; DON, R.; HAIGH, P.; PHILLIPS, G.; TONKIN, J.H.B.; WHEATON, O.E. Assessment of the repeatability of the controlled deterioration vigour test both within and between laboratories. Seed Science and Technology, v.12, n.2, p.421-427, 1984.

POWELL, A.A.; FERGUSON, A.J.; MATTHEWS, S. Identification of vigour differences among combining pea (Pisum sativum) seed lots. Seed Science and Technology, v.25, n.3, p.443-464, 1997.
ROBERTS, E.H. Predicting the storage life of seeds. Seed Science and Technology, v.1, n.3, p.499-514, 1973.

RODO, A.B.; PANOBIANCO, M.; MARCOS FILHO, J. Metodologia alternativa do teste de envelhecimento acelerado para sementes de cenoura. Scientia Agricola, v.57, n.2, p.289-292, 2000.

ROSSETO, C.A.V.; FERNANDEZ, E.M.; MARCOS FILHO, J. Metodologias de ajuste do grau de umidade e comportamento das sementes de soja no teste de germinação. Revista Brasileira de Sementes, v.17, n.2, p.171-178, 1995.

SILVA, J.B.; VIEIRA, R.D.; CECÍLIO FILHO, A.B. Superação de dormência em sementes de beterraba por meio de imersão em água corrente. Horticultura Brasileira, v.23, n.4, p.990-992, 2005.

SILVA, J.B.; VIEIRA, R.D.; PANOBIANCO, M. Accelerated ageing and controlled deterioration in beetroot seeds. Seed Science and Technology, v.34, n.2, p.265-271, 2006.

SWIADER, J.M.; WARE, G.W.; McCOLLUM, J.P. Producing vegetable crops. Danville: Interstate Publishers, 1992. 626p.

TEKRONY, D.M.; EGLI, D.B. Relationship between laboratory indices of soybean seed vigor and field emergence. Crop Science, v.17, n.4, p.573-577, 1977.

VÁSQUEZ, E.; MONTIEL, F.; VÁSQUEZ-RAMOS, J.M. DNA ligase activity in deteriorated maize axis during germination: a model relating effects in DNA metabolism in seeds to loss of germinability. Seed Science Research, v.1, n.2, p.269-273, 1991.

VIEIRA, R.D.; CARVALHO, N.M.; SADER, R. Testes de vigor e suas possibilidades de uso. In: VIEIRA, R.D.; CARVALHO, N.M. Testes de vigor em sementes. Jaboticabal: FUNEP, 1994. p.31-47. 